\title{
PERBEDAAN PENGARUH MEDIA BUKU POP-UP DAN LEAFLET TERHADAP PENGETAHUAN MENARKE PADA ANAK PEREMPUAN PUBERTAS AWAL
}

\section{THE DIFFERENCE OF MEDIA EFFECT POP-UP BOOK AND LEAFLET ON MENARCHE KNOWLEDGE IN EARLY PUBERTY GIRLS}

\author{
Khairun Nisa' Dewi', Rize Budi Amalia², Budi Utomo \\ 1. Program Studi Pendidikan Bidan, Fakultas Kedokteran, Universitas \\ Airlangga \\ 2. Fakultas Kedokteran, Universitas Airlangga \\ Alamat korespondensi: \\ Tangkis Selatan RT 016/RW 003 Banjarejo, Bojonegoro, Indonesia \\ Email: khairunnisadnr@gmail.com
}

\begin{abstract}
Abstrak
Latar Belakang :Menarke merupakan kondisi fisiologis berupa menstruasi pertama yang dialami perempuan. Kurangnya pengetahuan mengenai menarke berdampak pada ketidaksiapan dalam menghadapi menarke. Pendidikan kesehatan reproduksi dengan media yang sesuai dapat menjadi upaya meningkatkan pengetahuan tentang menarke. Penelitian ini bertujuan untuk menganalisis perbedaan pengaruh pemberian media buku pop-up dan leaflet terhadap peningkatan pengetahuan tentang menarke pada anak perempuan usia pubertas awal. Metode: Penelitian ini merupakan jenis kuasi experimental dengan pendekatan pretest-post test control group design. Jumlah sampel sebanyak 44 anak perempuan usia pubertas awal yang terbagi kedalam kelompok dengan intervensi media buku pop-up dan kelompok dengan intervensi media leaflet. Pengukuran pengetahuan tentang menarke menggunakan kuesioner pre-test dan post-test. Hasil: Uji Wilcoxon Signed Rank Test data pretest-postest pengetahuan pada kelompok yang diberi media leaflet $(\mathrm{p}=0,001)$ dan pretest-postest kelompok yang diberi media leaflet $(\mathrm{p}=0,001)$. Uji Mann Whitney U-Test data postest kelompok buku pop-up dan kelompok leaflet $(\mathrm{p}=0.002)(\mathrm{p}<0,05)$. Kesimpulan: Buku pop-up merupakan media yang lebih efektif dari leaflet untuk meningkatkan pengetahuan tentang menarke pada anak perempuan usia pubertas awal .
\end{abstract}

Kata kunci: Buku pop-up, Leaflet, Menarke, Pengetahuan, Pendidikan kesehatan reproduksi.

\section{Abstract}

Background: Menarche is physiological condition, the first menstruation that happen to women. Lack of knowledge can lead to unreadiness menstrual behaviour. Menstrual education by using visual media can be useful to increase menarche knowlede. This study aims to compare educational media of pop-up book and leaflet to increasing knowledge about menarche. Methods: The type of research was quasi experiment using pretest-posttest group design. The samples taken from 44 female students of SDN Banjarejo I dan II Bojonegoro. Samples consisting of 22 students as leaflet group and 22 students as pop-up book group. Method of measuring knowledge using pretest and postest questionnaire. Result: Wilcoxon Signed Rank Test indicate there was significant difference between pretest-posttest leaflet group $(p=0,001)$ and pretest-postest pop-up book group $(p=0,001)$. The result of Mann Whitney U-Test indicate there was significant difference of knowledge $(p=0,002)$ beetween postest leaflet group and postest pop-up book group. Conclusion: The conclusion of this study was the pop-up book was found more effective than leaflet in improving menarche knowledge. 
Keywords : Pop-up books, Leaflets, Menarche, Knowledge, Reproductive health education.

\section{PENDAHULUAN}

Menarke merupakan menstruasi pertama yang terjadi pada perempuan setelah perkembangan payudara dan pertumbuhan rambut pubis dan aksila (Jacqueline, 2018). Di Indonesia, anak perempuan rata rata mengalami menarke pada usia 12-14 tahun (Batubara, 2013). Hasil Riskesdas (2010) menunjukkan pada responden yang berusia 15-19 tahun mengalami menarke pada usia 13-14 tahun sebanyak 51,3\% dan yang dibawah usia 12 tahun sebanyak $30 \%$.

Kurangnya pengetahuan mengenai menarke dapat menjadi penghalang bagi perempuan untuk dapat percaya diri (Chandra, 2017). Anak perempuan usia pubertas awal yang tidak memiliki pengetahuan reproduksi yang baik cenderung menganggap menarke adalah sesuatu yang buruk sehingga berdampak pada munculnya kecemasan (Salins, 2018). Anak perempuan yang kurang pengetahuan reproduksinya dapat mengira bahwa menarke merupakan bukti adanya penyakit, menganggap diri kotor dan mengalami rasa malu. Trauma ini bisa terbawa sampai dewasa jika anak perempuan tidak diberikan informasi yang benar (Fitria, 2015). Pengetahuan tentang menarke yang kurang akan berpengaruh terhadap ketidaksiapan praktik menstrual hygiene (Permata, 2017). Selain itu kurangnya informasi mengenai anatomi tubuh, organ reproduksi dan menarke berdampak pada peningkatan insiden hubungan seksual yang berisiko (Emelumadu, 2014).

Tingkat pengetahuan tentang menarke pada anak perempuan usia pubertas awal mempengaruhi kesiapan menghadapi menarke. Rata-rata tingkat pengetahuan perempuan yang belum menghadapi menarke masih rendah (Lutfiya, 2016). Hasil sebuah penelitian menunjukkan sejumlah $33,8 \%$ anak perempuan yang berpengetahuan kurang seluruhnya mengalami ketidaksiapan dalam menghadapi menarke (Mutya, 2017). Penelitian oleh Linda (2013) menyebutkan bahwa gambaran pembelajaran tentang menstruasi pada anak perempuan baru didapatkan ketika keluar darah pertama kalinya. Sehingga menarke merupakan hal yang mengejutkan. Ketidaksiapan tersebut dikarenakan kurangnya informasi di lingkungan sekolah ditambah dengan sebagian besar orang tua yang tidak menyiapkan dan memberikan informasi mengenai menarke (Linda, 2013). 
Hasil studi pendahuluan yang dilakukan pada 30 siswi yang memasuki usia pubertas awal di Sekolah Dasar Bojonegoro dan belum mengalami menarke dengan menggunakan kuesioner pengetahuan tentang menstruasi didapatkan hasil $60 \%$ siswi berpengetahuan kurang, 37\% berpengetahuan cukup dan 3\% berpengetahuan baik. Kurangnya pengetahuan tersebut dikarenakan belum adanya satu program pendidikan dan pembekalan khusus yang dimiliki Sekolah Dasar Bojonegoro dalam meningkatkan pengetahuan tentang menarke pada anak perempuan usia pubertas awal.

Upaya meningkatkan pengetahuan tentang menarke memerlukan adanya proses pendidikan kesehatan reproduksi yang didukung oleh media atau alat bantu. Tujuan dari penelitian untuk menganalisis perbedaan pengaruh media pendidikan buku pop-up dan leaflet terhadap pengetahuan tentang menarke pada anak perempuan usia pubertas awal.

\section{METODE}

Tempat penelitian ini dilakukan di SDN Banjarejo 1 dan 2 Bojonegoro.

Desain penelitian menggunakan kuasi eksperimental dengan pendekatan pretestpost test control group design. Populasi dari penelitian ini adalah siswi SDN Banjarejo 1 dan 2 yang belum mengalami menarke dan telah memasuki usia telarke. Teknik sampling yang digunakan adalah probability sampling berdasarkan kriteria inklusi. Pada pelaksanaan penelitian, responden yang didapatkan sebanyak 44 responden yang dibagi menjadi 2 kelompok yakni kelompok responden yang diberi media buku pop-up dan kelompok responden yang diberi media leaflet.

Pengumpulan data dilakukan pada bulan Januari - Maret 2019 dimulai dengan penentuan sampel penelitian. Seluruh responden kelompok buku pop-up dan kelompok leaflet pada saat pretest dan postest mengisi kuesioner pengetahuan tentang menarke yang diadaptasi dari kuesioner penelitian sebelumnya (Lutfiya, 2016) untuk mendapatkan data primer.

Analisis data pada penelitian ini menggunakan uji Wilcoxon signed rank test terhadap data pretest-postest untuk mengetahui pengaruh media buku pop-up dan pengaruh media leaflet. Uji Mann Whitney U-test terhadap hasill postest untuk mengetahui perbedaan pengetahuan antara kelompok buku pop-up dan kelompok leaflet. 


\section{HASIL DAN PEMBAHASAN}

Tabel 1. Pengetahuan tentang menarke sebelum dan sesudah diberikan media

\begin{tabular}{lllllllllll}
\hline & & \multicolumn{4}{l}{ Kelompok Buku Pop-up } & \multicolumn{3}{c}{ Kelompok Leaflet } \\
\hline No & Tingkat & Pre & \multicolumn{3}{c}{ Post } & \multicolumn{3}{c}{ Pre } & \multicolumn{2}{c}{ Post } \\
& Pengetahuan & $\Sigma$ & $\%$ & $\Sigma$ & $\%$ & $\Sigma$ & $\%$ & $\Sigma$ & $\%$ \\
\hline 1. & Kurang & 12 & 54,6 & 0 & 0 & 10 & 45,5 & 6 & 27,3 \\
2. & Cukup & 6 & 27,2 & 3 & 13,6 & 9 & 40,9 & 3 & 13,6 \\
3. & Baik & 4 & 18,2 & 19 & 86,4 & 3 & 13,6 & 13 & 59,1 \\
& Total & 22 & 100 & 22 & 100 & 22 & 100 & 22 & 100
\end{tabular}

Berdasarkan hasil penelitian dapat diketahui bahwa pada saat pretest mayoritas responden memiliki pengetahuan dengan kategori kurang. Kelompok buku pop-up memiliki sejumlah 54,6\% berpengetahuan kurang. Kelompok leaflet memiliki sebesar $45,5 \%$ berpengetahuan kurang. Pada saat dilakukan posttest mayoritas responden memiliki pengetahuan yang baik. Pada kelompok buku popup sebesar 86,4\% berpengetahuan baik. Pada kelompok leaflet sebesar 59,1\% berpengetahuan baik.

Tabel 2. Durasi membaca media

\begin{tabular}{|c|c|c|c|c|c|}
\hline \multirow[b]{2}{*}{ Kelompok } & \multicolumn{3}{|c|}{ Durasi Membaca Media } & \multirow[b]{2}{*}{$\%$} & \multirow[b]{2}{*}{ Jumlah } \\
\hline & $\begin{array}{l}\leq \quad 15 \\
\text { menit }\end{array}$ & $\%$ & $\begin{array}{l}\geq 20 \\
\text { menit }\end{array}$ & & \\
\hline Buku pop-up & 2 & 9,1 & 20 & 90,9 & 22 \\
\hline Leaflet & 21 & 95,4 & 1 & 4,6 & 22 \\
\hline
\end{tabular}

Kedua kelompok diberikan durasi waktu membaca yang sama yakni 20-30 menit Berdasarkan tabel tersebut dapat diketahui bahwa mayoritas responden pada kelompok buku pop-up yakni sebanyak 90,9\% membaca media dengan waktu yang lebih lama yakni $\geq 20$ menit. Hal tersebut dikarenakan beberapa responden membaca ulang lembaran yang sudah dilewati dengan antusias. Sedangkan responden kelompok leaflet sebesar 95,4\% cenderung membaca dalam durasi yang lebih singkat yakni $\leq 15$ menit. Responden meletakkan media leaflet setelah membaca tanpa muncul keinginan untuk membaca dan mengamati ulang media leaflet sekalipun waktu yang diberikan masih tersisa. 
Tabel 3. Hasil analisis pengetahuan pretest dan posttest responden

\begin{tabular}{llllll}
\hline No & Kelompok & & $\mathrm{n}$ & $\mathrm{Z}$ & Nilai $\mathrm{p}$ \\
\hline 1. & Buku pop-up & $\begin{array}{l}\text { Pretest } \\
\text { Posttest }\end{array}$ & 22 & $-4,143$ & 0,001 \\
2. & Leaflet & $\begin{array}{l}\text { Pretest } \\
\text { Posttest }\end{array}$ & 22 & $-3,957$ & 0,001 \\
\hline
\end{tabular}

Hasil uji Wilcoxon Signed Rank Test kelompok yang diberi media buku popup menunjukkan hasil $\mathrm{p}(0,001)<\alpha$. Kelompok responden yang diberi media leaflet menunjukkan hasil p $(0,001)<\alpha$. Dapat disimpulkan kedua media memiliki pengaruh dalam meningkatkan pengetahuan tentang menarke.

Tabel 4. Hasil analisis perbedaan pengetahuan kelompok buku pop-up dan kelompok leaflet

\begin{tabular}{lcll}
\hline Kelompok & N & Mean Rank & Nilai p \\
\hline Posttest kelompok buku pop-up & 22 & 28,34 & \\
Posttest kelompok leaflet & 22 & 16,66 & 0,002 \\
\hline
\end{tabular}

Hasil uji Mann Whitney Test untuk membandingkan nilai posttest antara kelompok buku pop-up dan kelompok leaflet diperoleh $\mathrm{p}=0,002$, sehingga $\mathrm{p}<\alpha$ $(0,05)$ yang artinya media buku pop-up meningkatkan pengetahuan lebih signifikan dibandingkan media leaflet.

Pengetahuan merupakan hasil pengindraan manusia terhadap objek tertentu melalui indra yang dimilikinya. Pengetahuan dapat bertambah melalui pengalaman yang telah dilalui dan pendidikan yang pernah didapat dari media yang diindra (Notoatmodjo, 2014). Paparan informasi tentang menstruasi diperlukan untuk meningkatkan pengetahuan pada anak perempuan usia pubertas awal. Orang tua terlebih ibu memiliki peran penting dan tanggung jawab dalam memberikan informasi tentang menstruasi. Hal tersebut disebabkan karena anak perempuan cenderung merasa nyaman berinteraksi dengan ibu dalam bahasan tentang pubertas dan menarke (Agbemenu, 2018). Pengetahuan atau informasi yang didapatkan dari orang tua atau ibu memiliki pengaruh terhadap kesiapan anak perempuan dalam menghadapi menstruasi pertamanya. Akan tetapi, orang tua cenderung merasa tabu memberikan informasi mengenai pubertas dan menarke secara utuh. Orang tua juga 
merasa tidak memiliki kemampuan memberikan informasi yang tepat berkaitan dengan pendidikan seksual (Anggraeni, 2016).

Penyampaian Informasi untuk meningkatkan pengetahuan anak perempuan usia pubertas awal tentang menarke dapat ditunjang dengan keberadaan media pendidikan. Anak perempuan usia pubertas awal yakni berkisar antara usia kurang lebih 11 tahun berada pada tahap konkrit-operasional (Santrock, 2003). Perkembangan ini membuat anak lebih suka dengan sesuatu yang bisa dilihat. Media visual yang menarik akan memudahkan penyerapan informasi tentang menarke pada anak perempuan usia pubertas awal. Selain itu, media pendidikan yang sesuai juga akan memudahkan orang tua dalam mengatasi kendala berupa keterbatasan pengetahuan terkait informasi apa saja yang harus disampaikan kepada anak tentang menstruasi dan pubertas.

Uji Wilcoxon Signed Rank Test pada kelompok yang diberi media buku popup dan media lealfet menunjukkan hasil nilai $\mathrm{p}(0,001)$ kurang dari $\alpha$. Hal tersebut menunjukkan bahwa kedua media tersebut berpengaruh tehadap peningkatan pengetahuan responden tentang menarke. Adanya peningkatan pengetahuan setelah diberi media menunjukkan bahwa informasi yang diberikan dapat diterima dan disampaikan dengan baik pada responden.

Berdasarkan hasil uji Wilcoxon Signed Rank Test kelompok dengan media buku pop-up dan media leaflet keduanya memiliki pengaruh signifikan dalam meningkatkan pengetahuan pada responden. Meskipun demikian angka peningkatan rata rata pengetahuan kelompok responden yang diberikan intervensi buku pop-up lebih tinggi dibanding kelompok responden dengan intervensi media leaflet. Hasil uji statistik menggunakan uji Mann Whitney U Test terhadap hasil posttest kelompok media buku pop-up dan leaflet didapatkan hasil signifikasi $\mathrm{p}=$ 0,002 sehingga $\mathrm{p} \leq \alpha(0,05)$ yang berarti terdapat perbedaan pengetahuan yang signifikan antara kelompok buku pop-up dan kelompok leaflet setelah pemberian intervensi. Hal tersebut menunjukkan bahwa sekalipun kedua media memiliki pengaruh terhadap peningkatan pengetahuan responden, akan tetapi pemberian media buku pop-up lebih efektif dibandingkan dengan media leaflet dalam meningkatkan pengetahuan tentang menarke pada anak perempuan usia pubertas awal. 
Media leaflet merupakan media yang sering dijumpai dalam penyampain berbagai informasi ditengah masyarakat. Leaflet sering dimanfaatkan karena biaya cetak murah dan praktis (Mulidah, 2010). Buku pop-up merupakan salah satu media pendidikan kesehatan yang dikemas dengan efek atau bentuk 3 dimensi (Ukhtinasari, 2017). Buku pop-up terdiri dari potongan, tempelan, dan lipatan suatu gambar yang diletakkan antara 2 lipatan buku. Buku pop-up juga memiliki potensi gerak dan interaksi melalui penggunaan kertas seperti lipatan, gulungan, slide (Bluemel, 2012). Teknik pembuatan buku pop-up memiliki jenis yang bermacammacam, mulai dari teknik transformations yakni tampilan potongan kertas yang disusun secara vertical, peepshow tampilan yang tersusun dari serangkaian tumpukan kertas hingga pull-tabs yaitu sebuah tab kertas geser yang jika ditarik memperlihatkan gerakan gambaran baru (Siregar, 2016).

Media buku pop-up dan leflet keduanya dapat difungsikan sebagai media pendidikan kesehatan yang disusun berdasarkan prinsip bahwa indera manusia mampu menangkap pengetahuan atau informasi yang ada dalam media pendidikan (Notoatmodjo, 2012). Sekalipun demikian hasil dari Mann Whitney U Test menunjukkan bahwa buku pop-up merupakan media yang lebih efektif dibandingkan dengan media leaflet untuk meningkatkan pengetahuan tentang menarke. Hal tersebut dikarenakan respon berupa peningkatan pengetahuan dipengaruhi oleh seberapa media pendidikan sebagai stimulus mampu menghadirkan minat baca responden (Notoatmodjo, 2014). Berdasarkan tebel dua didapatkan minat membaca dari kelompok responden dengan media buku pop-up lebih tinggi dibanding kelompok responden dengan media leaflet.

Kekurangan media leaflet dibandingkan dengan buku pop-up adalah leaflet tidak dapat menstimulir efek gerak dan mudah terlipat (Mulidah, 2010). Stimulus efek gerak dan design yang timbul pada buku pop-up ketika buku terbuka menjadi kelebihan buku pop-up dalam menciptakan minat baca responden lebih baik daripada media leaflet. Visualisasi bentuk dan efek gerak pada media buku pop-up akan merangsang indera penglihatan dalam proses pembelajaran. Informasi yang terserap lebih banyak pada responden dengan media buku pop-up menjadikan rata rata peningkatan pengetahuan responden dengan media buku pop-up lebih tinggi dibandingkan dengan media leaflet. Hasil penelitian ini menunjukkan bahwa media 
buku pop-up dapat menjadi alternatif media yang digunakan untuk meningkatkan pengetahuan tentang menarke pada anak perempuan usia pubertas awal.

\section{SIMPULAN DAN SARAN}

Dapat disimpulkan bahwa terdapat pengaruh media buku pop-up terhadap peningkatan pengetahuan tentang menarke pada anak perempuan usia pubertas awal. Media buku pop-up dapat dimanfaatkan oleh orang tua dalam memberikan pendidikan kesehatan reproduksi tentang menarke untuk meningkatkan pengetahuan pada anak perempuan usia pubertas awal.

Sebaiknya pada penelitian selanjutnya dilakukan dengan menambah jumlah responden penelitian serta memastikan keseragaman kemampuan memahami responden terhadap kuesioner yang diberikan.

\section{DAFTAR PUSTAKA}

Agbemenu, K., Devido, J., Terry, M. A. (2018), 'Exploring the experience of african immigrant mothers providing reproductive health education to their daughters aged 10 to 14 years', Journal of transcultural nursing, 29(2), pp. 123-130.

Anggreni, D. (2016). Hubungan Antara Pola Pengasuhan Kesehatan Reproduksi Orang Tua Dengan Perilaku Kesehatan Reproduksi Anak Usia 10 dan 11 tahun di Kota Mojokerto. Tesis. Universitas Airlangga Surabaya.

Batubara, J.R., Soesanti, F. \& Waal, H.D. (2013) 'Age at menarche in Indonesian girls : A National Survey'. Acta Med Indonesia, 42(2), pp.78-81.

Bluemel, N.L., Taylor, R.H. (2013) 'Pop-up books : an introductory guide', Collect Build, 22(1), pp.21-32.

Chandra, Mouli, Venkatraman, Patel, Sheila, Vipul (2017) 'Mapping the knowledge and understanding of menarke, menstrual hygiene and menstrual health among adolescent girls in low and middle-Income countries', Reproductive Health, 4, pp. 1-16.

Emelumadu, O.F., Ezeama,N. N., Ifeadike, C.O., Ubajaka, C. F., Adogu, P. O., Umeh, U. (2014) 'Parents' perceptions of timing of initiation of sexuality discussion with adolescent in Anambra state, southeastern Nigeria', Journal of Pediatric and Adolescent Gynecology, 2, pp.294-300.

Fitria, G., (2015) Pengaruh penyuluhan menarke terhadap tingkat kecemasan menghadapi menarke siswi kelas V dan VI di SD Negeri Berbah 1 Sleman. Artikel, Stikes Aisyiyah Yogyakarta.

Jacqueline, Y., Maher, Howard A., Zacur. (2018) 'Encyclopedia of reproduction (second edition). Menarche/Menopause', Elsevier, 2, pp. 245-249.

Lutfiya, I. (2016). Pengaruh pola asuh orang tua terhadap kesiapan menghadapi menarke pada remaja putri pra-Pubertas. Skripsi Universitas Airlangga Surabaya 
Mutya, R. (2017). Faktor-faktor yang mempengaruhi pengetahuan dan kesiapan remaja putri dalam menghadapi menarke di SDN Wonorejo 6 Tempel Sukorejo, Surabaya. Skripsi. Universitas Airlangga Surabaya.

Notoatmodjo, S., (2012). Promosi kesehatan dan perilaku kesehatan. Jakarta : PT Rieneka Cipta.

Notoatmodjo, S., (2014). Ilmu perilaku kesehatan. Jakarta :PT Rieneka Cipta.

Permata, D. (2017). Hubungan pengetahuan dengan praktik menstrual hygiene pada anak dengan menarke dini. Skripsi. Universitas Airlangga Surabaya

Riset Kesehatan Dasar. 2010. Riskesdas 2010. Jakarta : Kementrian kesehatan Republik Indonesia

Salins, C.C., D’Souza, A., Nayak, M.G. (2018)'Knowledge, perception and psychococial preparedness for menarke among adolescent girls of Udupi District, Karnata', Indian Journal of Public Health Research and Development, 9(7), pp. 13-17.

Santrock, J.W. (2003). 'Children'. Boston : McGraw Hill.

Siregar, A, Rahmah, E. (2016). 'Model pop up book keluarga untuk mempercepat kemampuan membaca anak kelas rendah sekolah dasar', Jurnal Ilmu Informasi Perpustakaan dan Kearsipan, 5, pp.12.

Ukhtinasari. F., Mosik., Sugiyono. (2017). Pop up book sebagai media pembelajaran fisika materi alat-alat optikk untukk siswa sekolah menengah atas. Unnes Physical Education Journal, (6). 